\title{
The impact of right coronary artery support on outcomes of patients with unprotected left main disease undergoing percutaneous coronary intervention
}

\author{
Wojciech Jan Skorupski, Marek Grygier, Aleksander Araszkiewicz, Włodzimierz Skorupski, Stefan Grajek, \\ Małgorzata Pyda, Andrzej Siniawski, Przemysław Mitkowski, Maciej Lesiak, Marta Kałużna-Oleksy \\ Chair and $1^{\text {st }}$ Department of Cardiology, Poznan University of Medical Sciences, Poznań, Poland
}

\author{
Editorial \\ by Burzotta et al., \\ see p. 609 \\ Correspondence to: \\ Wojciech Skorupski, MD, \\ $1^{\text {st }}$ Department of \\ Cardiology, Poznan \\ University of Medical \\ Sciences, Poznań, Poland \\ Długa 1/2, 61-848 Poznań, \\ phone: +48 618549222 \\ e-mail: \\ wojtek.skorupski@wp.pl \\ Copyright by the \\ Author(s), 2021 \\ Kardiol Pol. 2021; \\ 79 (6): 631-637; \\ DOI: 10.33963/KP.15972 \\ Received: \\ December 1, 2020 \\ Revision accepted: \\ April 19, 2021 \\ Published online: \\ April 26, 2021
}

\begin{abstract}
A B S TR A C T
Background: Many operators are discouraged from performing left main (LM) percutaneous coronary interventions $(\mathrm{PCl})$ in the absence of right coronary artery $(\mathrm{RCA})$ support due to the increased procedure risk. Aims: We aimed at assessing the impact of absent functional RCA on prognostic implications in patients undergoing unprotected LM PCI.

Methods: 613 patients underwent LM PCI in our department between 2015 and 2019. Consecutive 385 patients with unprotected LM and at least 1-year follow-up were included in the study. The study population comprised 272 patients with unprotected left main coronary artery disease (ULMCAD) with dominant RCA, without any significant lesions (Group 1), and 113 ULMCAD patients and without RCA support (Group 2).

Results: In Group 2, 32.7\% patients had a significant RCA stenosis, 48.7\% had chronic total occlusion (CTO) of RCA, and $18.6 \%$ had recessive RCA. Patients in Group 2 were older and had higher prevalence of chronic obstructive pulmonary disease (COPD). SYNTAX Score (median [IQR] 26.0 [20.0-33.0] vs 19.0 [13.0-25.5]; $P<0.001$ ) was higher and left ventricular ejection fraction was lower (median [IQR] 50.0 $[40.0-60.0] \%$ vs $55.0[45.0-60.0] \% ; P=0.01$ ) in this group. All periprocedural complications did not differ among the groups. Long-term all-cause mortality at a median follow-up of 1149 days did not differ significantly ( $23 \%$ vs $20 \%$; $P=0.37$ ). The long-term mortality in CTO-RCA group was also not significantly different.
\end{abstract}

Conclusions: Patients with ULMCAD who have undergone LM PCI in the absence of RCA support, com-pared with those with ULMCAD and RCA support, differed neither in the prevalence of periprocedural complications nor in long-term all-cause mortality.

Kardiol Pol 2021; 79, 6: 631-637 Key words: left main, percutaneous coronary intervention, right coronary artery support

\section{INTRODUCTION}

Significant left main coronary artery (LM) lesions are detected in about $4 \%-9 \%$ of patients referred for coronary angiography [1, 2]. Advances in the field of percutaneous coronary interventions $(\mathrm{PCl})$ including proper patient selection, improvements in device technology, stenting techniques, and medical therapy post procedure have all made $\mathrm{PCl}$ a safe and effective alternative to coronary artery bypass graft (CABG) surgery for unprotected LM coronary artery disease (ULMCAD) [3-5].

$\mathrm{PCl}$ in ULMCAD has shown favorable results in large clinical trials and is being widely used worldwide [3, 5-10].
However, many operators are discouraged from performing $\mathrm{PCl}$ of the $\mathrm{LM}$ in the absence of right coronary artery (RCA) support to the left coronary circulation. This is due to a potentially increased risk of live-threatening periprocedural complications. It is a common belief, that in such cases occurrence of significant complications during $\mathrm{PCI}$ of LM can lead to complete deprivation of blood supply to the entire myocardium and may put the patient at an unacceptably high risk.

Chronic total occlusion (CTO) of the coronary artery is the most common reason for referring patients with LM stenosis requiring revascularization to $C A B G$ surgery [11-13] 
WHAT'S NEW?

To the best of our knowledge, this is the first study presenting the issue of unprotected left main (LM) percutaneous coronary intervention $(\mathrm{PCl})$ in the absence of functional right coronary artery (RCA) in the broad sense. Absence of RCA support was defined as presence of recessive RCA, significant stenosis of RCA or total occlusion of RCA. We found that patients with unprotected LM coronary artery disease PCI with absent RCA support had the same frequency of periprocedural complications and long-term all-cause mortality rate, as patients with unprotected LM coronary artery disease with RCA support. Therefore, PCI of LM could be a safe and effective procedure, also in patients with absence of RCA support.

which explains a relatively low incidence of CTO-RCA in previous randomized LM studies [14]. A similar issue also concerns the absence of RCA support, when a significant stenosis and/or an anatomically recessive variant of RCA is present. The impact of RCA support absence on the outcomes of patients undergoing $\mathrm{PCl}$ for unprotected $\mathrm{LM}$ disease continues to be of interest. The aim of the present study was to assess whether the absence of RCA circulation carries prognostic implications in patients undergoing unprotected LM PCI.

\section{METHODS}

Six hundred and thirteen patients who underwent $\mathrm{PCl}$ of LM in our department from January 2015 to June 2019 were included in the initial analysis. Consecutive 385 patients with unprotected LM and with at least 1-year follow-up were included in a prospective registry presented in this paper. Inclusion criteria were: presence of $\geq 50 \%$ diameter stenosis of unprotected LM with or without the involvement of the left anterior descending artery, ostial circumflex coronary artery (LCX), or both of the above. In patients with moderate lesions, the intravascular ultrasound imaging (IVUS) was used to confirm the significance of the stenosis, with a cut-off value of a minimal lumen area of $6.0 \mathrm{~mm}^{2}$. Terminal patients whose expected survival was less than one year were excluded from the study. The invasive procedures were performed after a Heart Team Meeting with a cardiac surgeon, by an experienced invasive cardiologists, at a high volume referral center with Cardiac Surgery Department on site.

The study group consisted of 272 patients with ULMCAD with dominant RCA, without any significant lesions (Group 1), and 113 patients with ULMCAD and without RCA support (Group 2). Absence of RCA support was defined as the presence of recessive RCA, significant stenosis of RCA, or total occlusion of RCA. A coronary artery system was classified as right dominant when the posterior descending artery (PDA) originated from the right coronary artery, while left dominance was defined as PDA originating from the LCX.

The clinical and angiographic data of these patients, including short- and long-term outcomes were analyzed. Baseline clinical data were collected for each patient at the index procedure. The main procedural data with all periprocedural and in-hospital complications were collected and analyzed. Chronic kidney disease was defined as decreased kidney function established on the basis of glomerular filtration rate $<60 \mathrm{ml} / \mathrm{min}$ for 3 months or more, calculated by the Cockcroft-Gault equation. All bifurcation lesions were classified angiographically according to the Medina classification [15]. Patients with LM equivalent disease, i.e., distal bifurcation Medina $0-1-1$, who presented $<70 \%$ stenoses of the ostial left anterior descending artery or LCx without any evidence of ischemia in its myocardial distribution, were not included in the study [5]. CTO-RCA was defined as complete occlusion of RCA with 0 flow lasting at least 3 months, regardless of the occlusion location. In patients with coexisting diseases of the LM and the RCA, the decision about the sequence of procedures was up to the operator's discretion. In the group with lack of RCA support the decision to treat LM prior to RCA was made. Patients were treated with the intention to achieve complete revascularization of all their major vessels bearing significant lesions; consequently they were scheduled for future procedures. The decision regarding CTO-RCA treatment was taken after $\mathrm{PCl}$ of LM. Therefore, all the analyzed patients in the CTO-RCA group at the time of analysis exhibited residual CTO. Some patients with LM lesions and concomitant RCA disease had RCA PCI prior to $\mathrm{LM} \mathrm{PCl}$ and were not included in the group with lack of RCA support. Periprocedural myocardial infarction (type 4a) was diagnosed based on European Society of Cardiology Fourth Universal Definition of Myocardial Infarction (2018) [16]. A glycoprotein Ilb/IIla receptor blocker, IVUS, and optical coherence tomography (OCT) were used at the operator's discretion. However, IVUS or OCT imaging were used in 118 (30.65\%) patients and were not analyzed in great detail. The antiplatelet regimens were low-dose aspirin (75 mg daily) and clopidogrel (75 mg daily) for a minimum of 6 months after $\mathrm{PCl}$, with the intention of 12 months of dual antiplatelet therapy.

The primary short-term outcome of the study was the composite of in-hospital death or myocardial infarction. Whereas, the long-term study end point was all-cause mortality. The median follow-up was 1149 days (max: 1650 days, interquartile range: 541 days). The data were collected by telephone or based on the official records of the National Health Fund. The registry conforms to the ethical guidelines of the 1975 Declaration of Helsinki and was granted ethics approval by the Institutional Review Board and the Bioethics Committee of the University. 
Statistical analysis was performed using STATISTICA 12 (Tibco Software Inc., Palo Alto, CA, USA). A standard descriptive statistics are presented as medians (interquartile range, $[\mathrm{QQR}])$. The normality distribution was analyzed using the Shapiro-Wilk test. The statistical significance of differences was tested with the nonparametric U Mann-Whitney test. Categorical variables were reported as counts or percentages and compared by tests for proportions. The Kaplan-Meier method was used to calculate the survival probability at follow-up. The survival curves were compared with the log-rank test. A two-sided $P$-value of $<0.05$ was considered significant for all the tests.

\section{RESULTS}

From the total cohort of 613 patients who underwent $\mathrm{PCI}$ of LM in our department, a total number of consecutive 385 unprotected LM PCl patients, with at least 1-year follow-up (median [IQR] age, 68.0 [62.0-76.0] years, 74.3\% male), were included in this analysis. Patient baseline characteristics are presented in Table 1. Patients with absence of RCA support (Group 2) were older (median [IQR], $69.0[64.0-78.0]$ vs $68.0[61.0-74.0]$ years; $P=0.03)$ and had higher prevalence of COPD ( $15.0 \%$ vs $6.3 \% ; P=0.006)$. The groups did not differ in other cardiovascular risk factors. Left ventricular ejection fraction (LVEF) was significantly lower in Group 2 (median [IQR], 50.0 [40.0-60.0] vs 55.0 [45.0-60.0]; $P=0.01$ ), with no significant differences in other echocardiographic parameters. Euroscore II was consequently higher in Group 2 (median [IQR], 2.01 [1.41-2.89] vs 1.20 [0.82-2.34]; $P=0.002$ ).

Coronary artery disease characteristics are shown in Table 2. Of the 113 patients from Group 2, 37 (32.7\%) had a significant stenosis of RCA, 55 (48.7\%) chronic total occlusion (CTO) of RCA, and 21 (18.6\%) recessive RCA. CTO of RCA with collateral circulation from left coronary artery (LCA) was described in 40 (35.4\%) patients from Group 2. Moreover, more patients in the Group with absent RCA support had severe disease of the LCX (39.8\% vs $27.2 \% ; P=0.02)$ and calcifications in LM $(20.4 \%$ vs $11.4 \%$; $P=0.02)$. SYNTAX Score was significantly higher in Group 2 (median [IQR], 26.0 [20.0-33.0] vs 19.0 [13.0-25.5]; $P$ $<0.001)$ and these patients more often required the use of two-stent techniques ( $29.2 \%$ vs $17.3 \% ; P=0.009$ ). Patients in Group 2 had more advanced atherosclerotic disease

Table 1. Baseline characteristics by the study group

\begin{tabular}{|c|c|c|c|c|}
\hline Variable & $\begin{array}{c}\text { Total } \\
(n=385)\end{array}$ & $\begin{array}{l}\text { Group } 1 \\
(n=272)\end{array}$ & $\begin{array}{l}\text { Group } 2 \\
(n=113)\end{array}$ & $\begin{array}{c}\text { P-value } \\
\text { (Group } 1 \text { vs Group 2) }\end{array}$ \\
\hline Age, years & $68.0(62.0-76.0)$ & $68.0(61.0-74.0)$ & $69.0(64.0-78.0)$ & 0.03 \\
\hline Gender, male & $286(74.3)$ & $198(72.8)$ & $88(77.9)$ & 0.30 \\
\hline $\mathrm{BMI}, \mathrm{kg} / \mathrm{m}^{2}$ & $27.8(24.9-30.8)$ & $28.1(25.1-31.1)$ & $27.2(24.3-30.2)$ & 0.24 \\
\hline Hypertension & $311(80.8)$ & $218(80.2)$ & $93(82.3)$ & 0.63 \\
\hline Hyperlipidemia & $190(49.4)$ & $135(49.6)$ & $55(48.7)$ & 0.86 \\
\hline CKD & $133(34.5)$ & $89(32.7)$ & $44(38.9)$ & 0.24 \\
\hline DM & $139(36.1)$ & $101(37.1)$ & $38(33.6)$ & 0.51 \\
\hline Stroke/TIA & $29(7.5)$ & $21(7.7)$ & $8(7.1)$ & 0.83 \\
\hline COPD & $34(8.8)$ & $17(6.3)$ & $17(15.0)$ & 0.006 \\
\hline PVD & $54(14.0)$ & $35(12.9)$ & $19(16.8)$ & 0.31 \\
\hline $\mathrm{AF}$ & $48(12.5)$ & $35(12.9)$ & $13(11.5)$ & 0.71 \\
\hline Cigarette smoking (current) & $143(37.1)$ & $98(36.0)$ & $45(39.8)$ & 0.48 \\
\hline Prior Ml & $181(47)$ & $127(46.7)$ & $54(47.8)$ & 0.84 \\
\hline Prior PCI LAD & $91(23.6)$ & $69(25.4)$ & $22(19.5)$ & 0.22 \\
\hline Prior PCI LCX & $55(14.3)$ & $36(13.2)$ & $19(16.8)$ & 0.36 \\
\hline Prior PCI RCA & $116(30.1)$ & $101(37.1)$ & $15(13.3)$ & $<0.001$ \\
\hline Prior CABG & $26(6.8)$ & $17(6.3)$ & $9(8.0)$ & 0.54 \\
\hline \multicolumn{5}{|l|}{ Clinical presentation } \\
\hline Stable angina & $220(57.1)$ & $159(58.5)$ & $61(54.0)$ & 0.42 \\
\hline Unstable angina & $113(29.4)$ & $80(29.4)$ & $33(29.2)$ & 0.97 \\
\hline NSTEMI & $37(9.6)$ & $22(8.1)$ & $15(13.3)$ & 0.12 \\
\hline STEMI & $11(2.9)$ & $8(2.9)$ & $3(2.7)$ & 0.88 \\
\hline LVEDD, mm & $50.0(47.0-55.0)$ & $50.0(47.0-55.0)$ & $50.5(46.0-56.0)$ & 0.65 \\
\hline LVEF, \% & $55.0(45.0-60.0)$ & $55.0(45.0-60.0)$ & $50.0(40.0-60.0)$ & 0.01 \\
\hline EuroScore II & $1.45(0.88-2.44)$ & $1.20(0.82-2.34)$ & $2.01(1.41-2.89)$ & 0.002 \\
\hline SYNTAX Score & $21.0(15.0-28.0)$ & $19.0(13.0-25.5)$ & $26.0(20.0-33.0)$ & $<0.001$ \\
\hline 0-22 (low) & $210(54.5)$ & $176(64.7)$ & $34(30.1)$ & $<0.001$ \\
\hline 23-32 (intermediate) & $117(30.4)$ & $67(24.6)$ & $50(44.2)$ & \\
\hline$\geq 33$ (high) & $58(15.1)$ & $29(10.7)$ & $29(25.7)$ & \\
\hline
\end{tabular}

Data are presented as number (percentage) of patients or median (IQR) unless otherwise indicated.

Abbreviations: AF, atrial fibrillation; BMI, body mass index; CABG, coronary artery bypass graft; CKD, Chronic Kidney Disease; COPD, chronic obstructive pulmonary disease; $D M$, diabetes mellitus; LAD, left anterior descending artery; $L C x$, left circumflex; LVEDD, left ventricular enddiastolic diameter; LVEF, left ventricular ejection fraction; MI, myocardial infarction; $\mathrm{PCl}$, percutaneous coronary intervention; PVD, peripheral vascular disease; RCA, right coronary artery; TIA, transient ischemic attack 
Table 2. Coronary artery disease characteristics

\begin{tabular}{|c|c|c|c|c|}
\hline Variable & $\begin{array}{c}\text { Total } \\
(n=385)\end{array}$ & $\begin{array}{l}\text { Group } 1 \\
(n=272)\end{array}$ & $\begin{array}{l}\text { Group } 2 \\
(n=113)\end{array}$ & $\begin{array}{l}\text { P-value (Group } 1 \text { vs } \\
\text { Group 2) }\end{array}$ \\
\hline LM distal & $312(81.0)$ & $219(80.5)$ & $93(82.3)$ & 0.68 \\
\hline LM bifurcation & $246(63.9)$ & $172(63.2)$ & $74(65.5)$ & 0.68 \\
\hline LM trifurcation & $44(11.4)$ & $27(9.9)$ & $17(15.0)$ & 0.15 \\
\hline LM calcification & $54(14.0)$ & $31(11.4)$ & $23(20.4)$ & 0.02 \\
\hline LAD disease (not ostial) & $192(49.9)$ & $129(47.4)$ & $63(55.8)$ & 0.14 \\
\hline LCx disease (not ostial) & $119(30.9)$ & $74(27.2)$ & $45(39.8)$ & 0.02 \\
\hline Protected LM & $0(0)$ & $0(0)$ & $0(0)$ & - \\
\hline RCA recessive (a) & $21(5.5)$ & $0(0)$ & $21(18.6)$ & $<0.001$ \\
\hline RCA with significant stenosis (b) & $37(9.6)$ & $0(0)$ & $37(32.7)$ & $<0.001$ \\
\hline RCA total occlusion (c) & $55(14.3)$ & $0(0)$ & $55(48.7)$ & $<0.001$ \\
\hline Lack of RCA support $(a+b+c)$ & $113(29.4)$ & $0(0)$ & $113(100)$ & $<0.001$ \\
\hline CTO of RCA with collateral circulation from LCA & $40(10.4)$ & $0(0)$ & $40(35.4)$ & $<0.001$ \\
\hline \multicolumn{5}{|l|}{ Extent of diseased vessels } \\
\hline LM plus 2-vessel disease & $93(32.6)$ & $47(17.3)$ & $46(40.7)$ & $<0.001$ \\
\hline LM plus 3-vessel disease & $29(7.5)$ & $0(0)$ & $29(25.7)$ & $<0.001$ \\
\hline \multicolumn{5}{|l|}{ Bifurcation medina } \\
\hline $1-0-0$ & $85(22.1)$ & $59(21.7)$ & $26(23.0)$ & 0.78 \\
\hline $1-0-1$ & $27(7.0)$ & $22(8.2)$ & $5(4.4)$ & 0.20 \\
\hline $1-1-0$ & $79(20.5)$ & $57(21.0)$ & $22(19.5)$ & 0.74 \\
\hline $1-1-1$ & $55(14.3)$ & $34(12.5)$ & $21(18.6)$ & 0.12 \\
\hline
\end{tabular}

Data are presented as number (percentage) of patients unless otherwise indicated.

Abbreviations: CTO, chronic total occlusion; LAD, left anterior descending artery; LCA, left coronary artery; LCx, left circumflex; LM, left main; RCA, right coronary artery

Table 3. Left main percutaneous coronary intervention (PCl) procedure characteristics and periprocedural outcomes

\begin{tabular}{|c|c|c|c|c|}
\hline Variable & $\begin{array}{c}\text { Total } \\
(\mathrm{n}=\mathbf{3 8 5})\end{array}$ & $\begin{array}{l}\text { Group } 1 \\
(n=272)\end{array}$ & $\begin{array}{l}\text { Group } 2 \\
(n=113)\end{array}$ & $\begin{array}{c}\text { P-value } \\
\text { (Group } 1 \text { vs Group 2) }\end{array}$ \\
\hline $\mathrm{PCl}$ success & $383(99.5)$ & $271(99.6)$ & $112(99.1)$ & 0.89 \\
\hline Number of stents & $2.0(1.0-2.0)$ & $1.0(1.0-2.0)$ & $2.0(1.0-2.0)$ & 0.12 \\
\hline Total length of implanted stents, $\mathrm{mm}$ & $33.0(23.0-48.0)$ & $32.0(23.0-47.0)$ & $39.0(23.0-56.0)$ & 0.07 \\
\hline Radiation time, $\min$ & $15.0(11.0-22.0)$ & $14.0(10.0-21.0)$ & $17.0(11.0-24.0)$ & 0.02 \\
\hline Radiation dose, mGy & $1237(813-1886)$ & $1237(826-1838)$ & $1238(734-2161)$ & 0.34 \\
\hline Contrast volume, $\mathrm{ml}$ & $220(180-300)$ & $215(180-300)$ & $230(180-300)$ & 0.43 \\
\hline \multicolumn{5}{|l|}{ Arterial access site } \\
\hline Radial & $238(61.8)$ & $166(61.0)$ & $72(63.7)$ & 0.62 \\
\hline Femoral & $147(38.2)$ & $106(39.0)$ & $41(36.3)$ & \\
\hline Stenting LM only & $48(12.5)$ & $35(12.9)$ & $13(11.5)$ & 0.71 \\
\hline \multicolumn{5}{|l|}{ Stenting LM bifurcation } \\
\hline One-stent technique & $257(66.8)$ & $190(69.9)$ & $67(59.3)$ & 0.045 \\
\hline Two-stents technique & $80(20.8)$ & $47(17.3)$ & $33(29.2)$ & 0.009 \\
\hline Two-stents techniques & Total, $\mathrm{n}=80$ & $\mathrm{n}=47$ & $\mathrm{n}=33$ & \\
\hline Crush & 27 (33.8) & $14(29.8)$ & $13(39.4)$ & 0.37 \\
\hline DK-Crush & $11(13.8)$ & $7(14.9)$ & $4(12.1)$ & 0.98 \\
\hline Cullote & $1(1.3)$ & $1(2.1)$ & $0(0)$ & 0.86 \\
\hline T-stenting & $17(21.3)$ & $10(21.3)$ & $7(21.2)$ & 0.99 \\
\hline Provisional stenting & $24(30)$ & $15(31.9)$ & $9(27.3)$ & 0.67 \\
\hline \multicolumn{5}{|l|}{ Periprocedural outcomes } \\
\hline Myocardial infarction & $18(4.7)$ & $14(5.2)$ & $4(3.5)$ & 0.50 \\
\hline In-hospital Death & $2(0.5)$ & $2(0.7)$ & $0(0)$ & 0.36 \\
\hline Stroke & $1(0.3)$ & $1(0.4)$ & $0(0)$ & 0.65 \\
\hline Tamponade & $2(0.5)$ & $0(0)$ & $2(1.8)$ & 0.09 \\
\hline Pulmonary oedema & $1(0.3)$ & $0(0)$ & $1(0.9)$ & 0.29 \\
\hline Dissection of aorta & $1(0.3)$ & $0(0)$ & $1(0.9)$ & 0.29 \\
\hline Perforation of femoral artery & $1(0.3)$ & $1(0.4)$ & $0(0)$ & 0.65 \\
\hline Contrast induced nephropathy & $16(4.2)$ & $11(4.0)$ & $5(4.4)$ & 0.91 \\
\hline
\end{tabular}

Data are presented as number (percentage) of patients or median (IQR) unless otherwise indicated.

Abbreviations: DK-Crush, double kissing crush technique; LM, left main; $\mathrm{PCl}$, percutaneous coronary intervention 


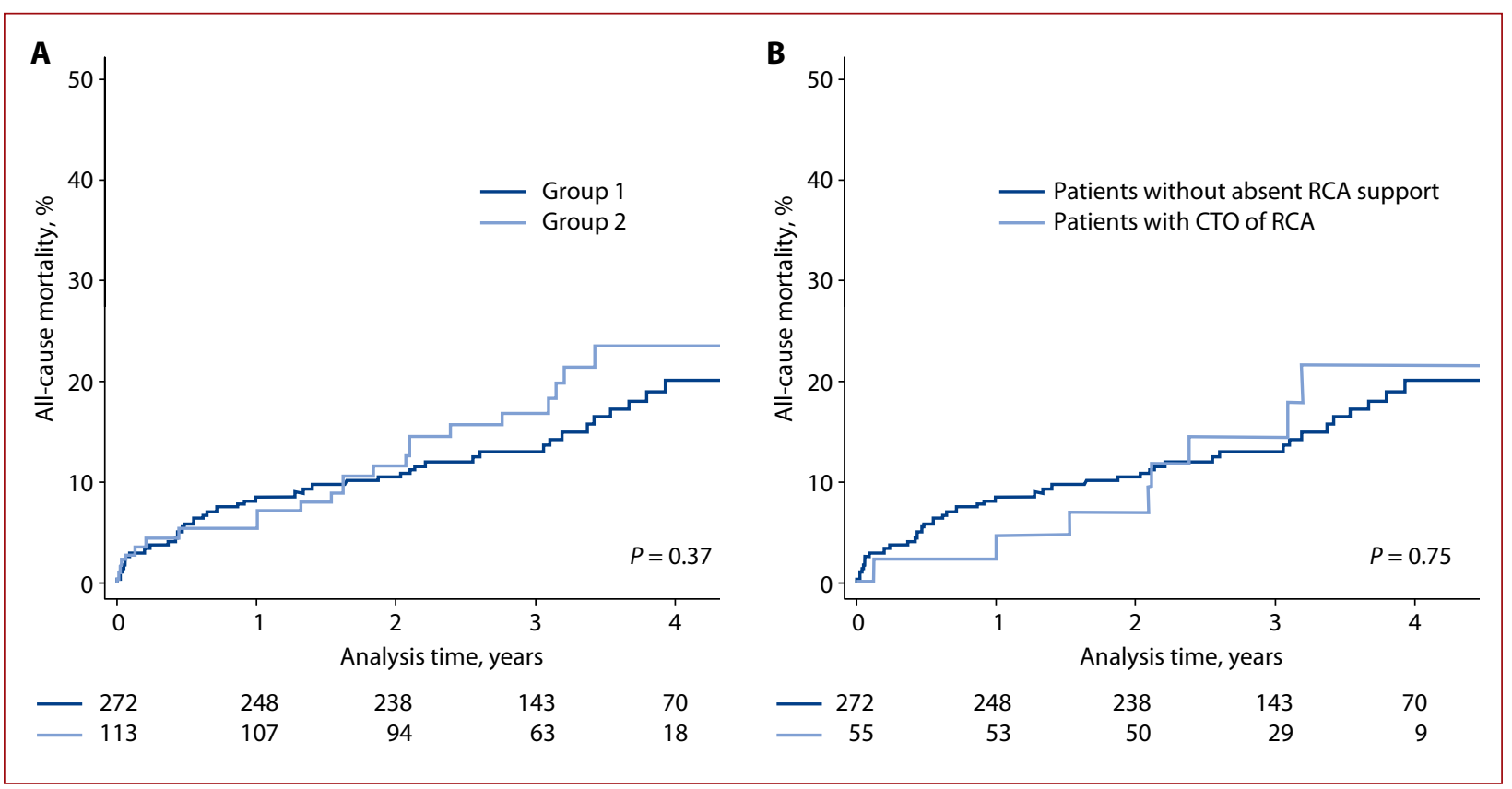

Figure 1. A. Kaplan-Meier analysis of all-cause mortality: Group 1 (patients with dominant RCA and without any significant lesions) vs Group 2 (patients with ULMCAD and absence of RCA support). B. Kaplan-Meier analysis of all-cause mortality: patients with RCA support vs patients with CTO of RCA. Abbreviations: see Table 1

and procedure radiation time was higher (median [IQR], 17.0 [11.0-24.0] min vs 14.0 [10.0-21.0] $\mathrm{min} ; P=0.02$ ). Various stenting techniques were used. No significant differences in the frequency of use of selected stenting techniques were observed (Table 3). All LM lesions were stented with second-generation drug-eluting stents (DES). Number of stents and total length of implanted stents did not differ significantly between the two groups. Artery access was similar and it was more often radial approach in both groups. An early success rate was very high (99\%) and did not differ between the groups. All LM procedures were carried out without left ventricular assist devices.

Periprocedural clinical outcomes are summarized at the end of Table 3. Frequency of all the perioperative complications $(9.7 \%$ vs $8.1 \% ; P=0.60)$ was similar in both study groups. Periprocedural mortality and myocardial infarction (type 4a) did not differ between the groups. Long-term all-cause mortality did not differ significantly ( $23 \%$ vs $20 \%$; $P=0.37$ ) between the two study groups either (Figure 1A).

In subanalysis, long-term mortality in patients with CTO of RCA was not different compared to the patients without absent RCA support ( $22 \%$ vs $20 \%$; $P=0.75$ ) (Figure 1 B). The incidence of perioperative complications in the group of patients with CTO-RCA, compared to the patients without absence of RCA support, was also not different $(9.09 \%$ vs $8.09 \% ; P=0.82$ ).

\section{DISCUSSION}

The main conclusion of the study is the fact that absence of RCA support during PCI of LM was not associated with an increased number of periprocedural complications and in-hospital mortality, and in the presence of such circum- stances the procedure is still deemed safe. However, it should be highlighted that there exists a risk of complications and such complex procedures, especially in absence of RCA support, should be performed in high-volume reference centers with quick access to cardiac surgery and the eventual use of left ventricular assist devices [17, 18].

Several papers have been published showing long-term outcomes of PCl of LM in presence of CTO-RCA [19-21], however, they were restricted only to the patients with СTO. The papers did not deal with the lack of RCA support in a situation of recessive or significantly stenotic RCA. To the best of our knowledge, the present study is the first one which raises the issue of unprotected $L M P C l$ in the absence of functional RCA in the broad sense.

The analysis of population from the EXCEL study shows that among 1753 patients included in the study, an occluded RCA at baseline was present in 130 patients (7.4\%) [19], which was analogous to our analysis, where CTO-RCA was noted in $14.3 \%$ of the patients. In EXCEL, the patients with an occluded RCA more frequently had a peripheral vascular disease, prior $\mathrm{PCl}$, lower LVEF, and a significantly higher SYNTAX Score [19]. However, the frequency of comorbidities in our real-life study was much higher than in the groups from the randomized EXCEL trial, where diabetes and renal insufficiency occurred in $33.6 \%$ vs $27.7 \%$ and $38.9 \%$ vs $14.4 \%$ respectively. It must be pointed out that frequency of periprocedural myocardial infarction was similar in both groups. Also, the success of LM angioplasty did not differ in both groups, despite an increased difficulty of the procedures in patients in Group 2.

Absence of RCA support (similarly to CTO-RCA) had no influence on long-term outcomes. The data from our 
real-world cohort study are in line with the results obtained in the EXCEL trial, where the presence of occluded RCA was also not independently associated with a higher 30-day, or a 3-year MACCE risk (a composite of death from any cause, e.g. stroke or myocardial infarction) [19]. These results are, however, contrary to these presented by other authors. In the prospective registry (involving 78 patients with CTO-RCA and ULMCAD) that assessed the impact of CTO-RCA in patients undergoing unprotected LM PCl, Migliorini et al. [20] showed that the CTO-RCA is a significant predictor of mortality in patients with ULMCAD undergoing $\mathrm{PCl}$. This major difference may result from older age (71 years vs 69 years) and more likely from lower LVEF (39.0\% vs 45\%) in the study by Migliorini et al. [20]. Similar findings to those by Migliorini et al. [20] were presented by Takagi et al. [21]. In their study (75 patients with (TO-RCA), cardiac death occurred more frequently in patients with residual CTO-RCA, as compared to those without residual CTO-RCA. Takagi et al. [21] also showed that recanalization of CTO-RCA had a significant impact on long-term cardiac-mortality in patients undergoing ULMCAD PCl, probably due to retrograde coronary circulation in these patients, in the event of LM stent restenosis. It is noteworthy that 5-year all-cause mortality in patients with residual CTO in the study by Takagi et al. [21] was relatively high, reaching up to $31 \%$ - this result, however, may be the consequence of a large proportion of patients with chronic kidney disease (60.9\%) in this group and the use of first generation DES.

Our study focuses not only on CTO-RCA, which in an obvious way increases SYNTAX Score and correlates with a more severe clinical condition, but unlike other studies, it also deals with the issues of the absence ofthe RCA support and performing high-risk procedures in the presence of only functional left coronary artery. In some cases, the presence of significant stenosis in RCA only slightly affects the SYNTAX Score, but in real-life practice it significantly increases the risk of the procedure. Interestingly, in Group 2 in our study, significantly more frequent use of two-stent techniques was observed, which probably results from advanced atherosclerotic disease in all coronary arteries and higher percentage of LM plus 2- and 3-vessel disease. Higher incidence of diffuse coronary atherosclerosis may result in an incomplete revascularization $\mathrm{PCl}$, and a large survey study in the DES era revealed that incomplete revascularization associated with CTO carries a worse prognosis and a higher risk of death, compared with complete revascularization [22]. In our study, we treated patients with the intention of achieving total revascularization, however, the decision to treat CTO-RCA, as well as severe stenosis of RCA, was undertaken after $\mathrm{LM} \mathrm{PCI}$ and was performed at a later stage.

In summary, the most important conclusion of our study is that angioplasty in patients in the absence of RCA support is a safe procedure that does not significantly increase the incidence of complications. Our study includes real-life patients and proves that the absence of RCA support or CTO-RCA does not necessarily significantly increase long-term mortality.

\section{Study limitations}

The presented study is an analysis of a real-world cohort of patients. One limitation of the study involves the lack of a surgical group. However, the comparison of such a group with the CABG group was beyond the scope of this study. Secondly, although the presented study was a prospective registry, not all clinical data were available. Thirdly, the analyzed population was a population of patients treated in a real-word setting, therefore, many patients with ULMCAD had multivessel disease and PCI was not just about $\mathrm{LM}$, which can influence the prognosis. Finally, the present study analyzed in-hospital, as well as long-term follow-up with the median observation time of over 3 years. However, the long-term follow-up assessed all-cause mortality and we were not able to show cardiovascular vs non-cardiovascular death rates analysis.

\section{CONCLUSIONS}

Patients with ULMCAD who have undergone $\mathrm{LM} \mathrm{PCI}$ with absent RCA support, compared with patients with ULMCAD with RCA support, differed neither in the frequency of periprocedural complications nor in long-term all-cause mortality.

These findings suggest that $\mathrm{PCl}$ of $\mathrm{LM}$ could be a safe and effective procedure, also in patients without RCA support.

\section{Article information}

Conflict of interest: None declared.

The abstract was published in the Journal of the American College of Cardiology abstracts book: https://doi.org/10.1016/j.jacc.2020.09.326

Open access: This article is available in open access under Creative Common Attribution-Non-Commercial-No Derivatives 4.0 International (CC BY-NC-ND 4.0) license, allowing to download articles and share them with others as long as they credit the authors and the publisher, but without permission to change them in any way or use them commercially. For commercial use, please contact the journal office at kardiologiapolska@ptkardio.pl.

How to cite: Skorupski WJ, Grygier M, Araszkiewicz A, et al. The impact of right coronary artery support on the outcomes of patients with unprotected left main disease undergoing percutaneous coronary intervention. Kardiol Pol. 2021; 79(6):631-637, doi: 10.33963/KP.15972.

\section{REFERENCES}

1. El-Menyar AA, AI Suwaidi J, Holmes DR. Left main coronary artery stenosis: state-of-the-art. Curr Probl Cardiol. 2007; 32(3): 103-193, doi: 10.1016/j. cpcardiol.2006.12.002, indexed in Pubmed: 17382834.

2. Hitchcock JF, Robles de Medina EO, Jambroes G. Angioplasty of the left main coronary artery for isolated left main coronary artery disease. JThorac Cardiovasc Surg. 1983; 85(6): 880-884, indexed in Pubmed: 6222222.

3. Morice MC, Serruys $P$, Kappetein AP, et al. Outcomes in patients with de novo left main disease treated with either percutaneous coronary intervention using paclitaxel-eluting stents or coronary artery bypass graft treatment in the synergy between percutaneous coronary intervention with TAXUS and cardiac surgery (SYNTAX) trial. Circulation. 2010; 121(24): 2645-2653, doi: 10.1161/circulationaha.109.899211. 
4. Park SJ, Kim YH, Park DW, et al. Randomized trial of stents versus bypass surgery for left main coronary artery disease. N Engl J Med. 2011; 364(18): 1718-1727, doi: 10.1056/NEJMoa1100452, indexed in Pubmed: 21463149.

5. Stone GW, Sabik JF, Serruys PW, et al. Everolimus-eluting stents or bypass surgery for left main coronary artery disease. NEngl J Med. 2016; 375(23): 2223-2235, doi: 10.1056/nejmoa1610227, indexed in Pubmed: 27797291.

6. Mäkikallio T, Holm NR, Lindsay M, et al. NOBLE study investigators. Percutaneous coronary angioplasty versus coronary artery bypass grafting in treatment of unprotected left main stenosis (NOBLE): a prospective, randomised, open-label, non-inferiority trial. Lancet. 2016; 388(10061): 2743-2752, doi: 10.1016/S0140-6736(16)32052-9, indexed in Pubmed: 27810312.

7. Ahn JM, Roh JH, Kim YH, et al. Randomized trial of stents versus bypass surgery for left main coronary artery disease: 5 -year outcomes of the PRECOMBAT study. J Am Coll Cardiol. 2015;65(20):2198-2206, doi: 10.1016/j. jacc.2015.03.033, indexed in Pubmed: 25787197.

8. Buszman PE, Buszman PP, Kiesz RS, et al. Early and long-term results of unprotected left main coronary artery stenting: the LE MANS (Left Main Coronary Artery Stenting) registry. J Am Coll Cardiol. 2009; 54(16): 1500 1511, doi: 10.1016/j.jacc.2009.07.007, indexed in Pubmed: 19699048.

9. ParkDW, Seung KB, Kim YH, et al. Long-term safety and efficacy of stenting versus coronary artery bypass grafting for unprotected left main coronary artery disease: 5-year results from the MAIN-COMPARE (Revascularization for Unprotected Left Main Coronary Artery Stenosis: Comparison of Percutaneous Coronary Angioplasty Versus Surgical Revascularization) registry. J Am Coll Cardiol. 2010; 56(2): 117-124, doi: 10.1016/j.jacc.2010.04.004, indexed in Pubmed: 20451344.

10. Kowalewski M, Gozdek M, Zieliński K, et al. Long-term mortality after percutaneous coronary intervention with drug-eluting stents compared with coronary artery bypass grafting for multivessel and left main disease: a meta-analysis. Kardiol Pol. 2020; 78(7-8): 759-761, doi: 10.33963/KP.15397, indexed in Pubmed: 32483953.

11. Abbott JD, Kip KE, Vlachos HA, et al. Recent trends in the percutaneous treatment of chronic total coronary occlusions. Am J Cardiol. 2006; 97(12): 1691-1696, doi: 10.1016/j.amjcard.2005.12.067, indexed in Pubmed: 16765115.

12. Grantham JA, Marso SP, Spertus J, et al. Chronic total occlusion angioplasty in the United States. JACC Cardiovasc Interv. 2009; 2(6): 479-486, doi: 10.1016/j.jcin.2009.02.008, indexed in Pubmed: 19539249.

13. Christofferson RD, Lehmann KG, Martin GV, et al. Effect of chronic total coronary occlusion on treatment strategy. Am J Cardiol. 2005; 95(9): 1088-1091, doi: 10.1016/j.amjcard.2004.12.065, indexed in Pubmed: 15842978 .
14. Serruys PW, Morice MC, Kappetein AP, et al. SYNTAX Investigators. Percutaneous coronary intervention versus coronary-artery bypass grafting for severe coronary artery disease. N Engl J Med. 2009; 360(10): 961-972, doi: 10.1056/NEJMoa0804626, indexed in Pubmed: 19228612.

15. Medina A, Suárez de Lezo J, Pan M. A new classification of coronary bifurcation lesions. Rev Esp Cardiol. 2006; 59(2): 183, doi: 10.1016/s18855857(06)60130-8, indexed in Pubmed: 16540043.

16. Thygesen K, Alpert JS, Jaffe AS, et al. Executive Group on behalf of the Joint European Society of Cardiology (ESC)/American College of Cardiology (ACC)/American Heart Association (AHA)/World Heart Federation (WHF) Task Force for the Universal Definition of Myocardial Infarction. Fourth Universal Definition of Myocardial Infarction (2018). J Am Coll Cardiol. 2018; 72(18): 2231-2264, doi: 10.1016/j.jacc.2018.08.1038, indexed in Pubmed: 30153967.

17. Aragon J, Lee MS, Kar S, et al. Percutaneous left ventricular assist device: "TandemHeart" for high-risk coronary intervention. Catheter Cardiovasc Interv. 2005; 65(3): 346-352, doi: 10.1002/ccd.20339, indexed in Pubmed: 15945107.

18. Bonvini RF, Hendiri T, Camenzind E, et al. High-risk left main coronary stenting supported by percutaneous left ventricular assist device. Catheter Cardiovasc Interv. 2005; 66(2): 209-212, doi: 10.1002/ccd.20466, indexed in Pubmed: 16152645.

19. Chen S, Karmpaliotis D, Redfors B, et al. Does an occluded RCA affect prognosis in patients undergoing $\mathrm{PCl}$ or $\mathrm{CABG}$ for left main coronary artery disease? Analysis from the EXCEL trial. Eurolntervention. 2019; 15(6): e531-e538, doi: 10.4244/eij-d-19-00263, indexed in Pubmed: 31186220.

20. Migliorini A, Valenti R, Parodi G, et al. The impact of right coronary artery chronic total occlusion on clinical outcome of patients undergoing percutaneous coronary intervention for unprotected left main disease. J Am Coll Cardiol. 2011; 58(2): 125-130, doi: 10.1016/j.jacc.2011.02.050, indexed in Pubmed: 21718907.

21. Takagi K, lelasi A, Chieffo A, et al. Impact of residual chronic total occlusion of right coronary artery on the long-term outcome in patients treated for unprotected left main disease: the Milan and New-Tokyo registry. Circ Cardiovasc Interv. 2013; 6(2): 154-160, doi: 10.1161/CIRCINTERVENTIONS.112.000079, indexed in Pubmed: 23572491.

22. Hannan EL, Wu C, Walford G, et al. Incomplete revascularization in the era of drug-eluting stents: impact on adverse outcomes. JACC Cardiovasc Interv. 2009; 2(1): 17-25, doi: 10.1016/j.jcin.2008.08.021, indexed in Pubmed: 19463393. 